\title{
GESTÃO AMBIENTAL PROATIVA
}

\author{
Carmen Silvia Sanches \\ Economista pela Unicamp, Mestre e \\ Doutoranda em Administração de \\ Empresas pela EAESP/FGV. \\ E-mail: csanches@fgvsp.br
}

\section{RESUMO}

As empresas industriais que procuram manter-se competitivas ou mesmo sobreviver e se ajustar a um ambiente de negócios turbulento e imprevisível percebem cada vez mais que, diante das questões ambientais, são exigidas novas posturas, num processo de renovação contínua, seja na maneira de operar seus negócios, seja em suas organizações. Nesse sentido, as empresas industriais estão desenvolvendo novas formas de lidar com os problemas ambientais, mediante mecanismos de auto-regulação ou por meio de uma gestão ambiental proativa.

\begin{abstract}
Industrial companies that look for a competitive advantage or to even survive and to adjust to a turbulent and unforeseeable business environment realize that they need to increasingly strike new attitudes related to environmental problems. These new attitudes include a continuous changing process on the manner to manage their business in the organizations. Thus, some industrial companies are developing new ways to deal with the environmental problems through auto-regulation mechanisms or proactive environmental management.
\end{abstract}

\section{PALAVRAS-CHAVE}

Auto-regulação, empresa proativa, estratégia de negócios e meio ambiente, tecnologias ambientais, instrumentos de gestão ambiental.

\section{KEY WORDS}

Auto-regulation, proactive company, business strategy and environment, environmental technologies, environmental management tools. 


\section{INTRODUÇÃO}

O ambiente de negócios na década de 90 tem-se mostrado bastante instável e turbulento, verificando-se a existência de mudanças bastante drásticas no processo econômico e produtivo mundial, com implicações diretas para as empresas industriais. Fatos como transformações na economia internacional e globalização da produção e do consumo têm sido acompanhados de outras mudanças como, por exemplo, um crescente grau de exigência dos consumidores, que, por meio de seu poder de compra, estão buscando variedade de produtos, demonstrando a sua preocupação pela qualidade e manifestando uma constante exigência para melhorar o binômio preço-desempenho.

A emergência desse consumidor mais agressivo e exigente reflete em grande parte as mudanças que a própria sociedade vem sofrendo quanto a valores e ideologias e que envolvem suas expectativas em relação às empresas e aos negócios. Esses novos valores e ideologias incluem a democracia, a igualdade de oportunidades, a saúde e a segurança no trabalho, a proteção ao consumidor, um meio ambiente mais limpo, entre outras questões. Seja como consumidores, ou como trabalhadores, ou ainda por meio do governo ou da mídia, a sociedade tem pressionado para que as empresas incorporem esses valores em seus procedimentos operacionais. Como conseqüência, as empresas estão se deparando com um ambiente externo em que cada vez mais as questões sociais, políticas e legais, inexistentes ou apenas latentes em períodos anteriores, adquirem uma nova perspectiva administrativa.

As empresas industriais que procuram manter-se competitivas ou mesmo sobreviver e se ajustar a esse novo ambiente de negócios, que já se mostra bastante concorrido, marcado por incertezas, instabilidades e rápidas mudanças, percebem cada vez mais que, diante das questões ambientais, são exigidas novas posturas, seja na maneira de operar seus negócios, seja em suas organizações. Essa renovação implica contínuas mudanças, que podem ser dolorosas e custosas também em termos financeiros, especialmente se forem impostas, como por meio de regulamentações ambientais, ou se provierem de uma imagem pública negativa, como por atritos com comunidades locais ou um desastre ambiental. Essas mudanças podem, ainda, ser gerenciadas internamente mediante mecanismos de auto-regulação ou por ações individuais, como será visto a seguir.

\section{AS EMPRESAS INDUSTRIAIS}

QUE PROCURAM MANTER-SE

COMPETITIVAS PERCEBEM

CADA VEZ MAIS QUE, DIANTE

DAS QUESTÕES AMBIENTAIS,

SÃO EXIGIDAS NOVAS

POSTURAS, NUM PROCESSO

DE RENOVAÇÃO CONTÍNUA.

\section{A AUTO-REGULAÇÃO}

A auto-regulação representa iniciativas tomadas pelas empresas ou por setores da indústria para empreender e disseminar práticas ambientais que promovam uma maior responsabilidade das empresas quanto às questões ambientais, mediante a adoção de padrões, monitorações, metas de redução da poluição e assim por diante. Num sentido mais amplo, pode-se dizer que é uma das diversas maneiras de equilibrar as forças de mercado e distribuir de maneira mais justa, em termos monetários, os danos que a sociedade está suportando como efeito da modificação da qualidade do meio ambiente.

A auto-regulação tem-se apresentado sob diversas formas. Uma delas são os acordos voluntários, que têm sido usados desde a década de 70, especialmente em países desenvolvidos, algumas vezes para complementar e tornar mais fortes as regulamentações já existentes. Trata-se de contratos entre autoridades públicas (por exemplo, o Ministério ou a Secretaria do Meio Ambiente) e a indústria (uma associação industrial ou uma firma individual) ou entre uma firma e uma municipalidade ou associação de moradores locais, sob os quais as indústrias ou firmas se comprometem a alcançar uma série de objetivos ambientais. Os contratos têm a força de lei privada, somente, e não acarretam 
penalidades legais pela quebra de seus termos. Algumas de suas vantagens, sob o ponto de vista da indústria, relacionam-se ao fato de oferecerem um incentivo para as firmas investirem em processos de produção mais adequados, em vez de se submeterem aos objetivos ambientais impostos por autoridades governamentais, além de concederem uma imagem pública mais positiva da indústria para os governos, as comunidades locais e a própria sociedade (Potier, 1994).

\section{TRATA-SE, TODAS AS} FORMAS DE AUTO-

REGULAÇÃO, DE INICIATIVAS
QUE MARCAM UM NOVO
CONTEXTO DE PARTICIPAÇÃO
DO EMPRESARIADO RUMO
À CONSCIÊNCIA E ÀS
RESPONSABILIDADES
AMBIENTAIS.

Outra forma de auto-regulação, mais recentemente utilizada, são os princípios e códigos de condutas empresariais internacionais, como o Programa Atuação Responsável (Responsible Care) da indústria química, elaborado em 1985 no Canadá e disseminado em diversos outros países, inclusive no Brasil, pelas associações nacionais do setor; os Princípios Ceres (antigamente chamados Princípios Valdez), que datam de 1989, mas com uma nova versão de 1992; o Keidaren Global Environment Charter, organizado no Japão em 1991; a Carta de Princípios para o Desenvolvimento Sustentável, lançada pela Câmara Internacional de Comércio (CIC) em 1991, entre outros.

Também se enquadram nas iniciativas de autoregulação as parcerias formadas entre empresas, como, por exemplo, o Compromisso Empresarial para a Reciclagem (Cempre), com empresas nacionais e multinacionais voltadas para o desenvolvimento e a capacitação da indústria brasileira nessa área; ou a Gemi (Global Environmental Management Initiative), uma "rede de negócios verdes" sediada em Washington, Estados Unidos, formada por 20 empresas norte-americanas de grande porte, como a Procter \& Gamble, a AT\&T, entre outras, interessadas em promover a implementação da Carta da CIC e (com)partilhar as melhores práticas de gestão ambiental.

Trata-se, todas as formas de autoregulação, de iniciativas que marcam um novo contexto de participação do empresariado rumo à consciência e às responsabilidades ambientais, também com a preocupação de adequar os princípios de sustentabilidade à realidade dos mercados em que as empresas estão inseridas.

\section{A POSTURA PROATIVA}

A auto-regulação também se estende a empresas agindo por sua própria iniciativa e interessadas no desempenho de seus próprios negócios. Nesse sentido, empresas industriais adotam posturas proativas em relação ao meio ambiente mediante a incorporação dos fatores ambientais nas metas, políticas e estratégias da empresa, considerando os riscos e os impactos ambientais não só de seus processos produtivos mas também de seus produtos. Assim, a proteção ambiental passa a fazer parte de seus objetivos de negócios e o meio ambiente não é mais encarado como um adicional de custo, mas como uma possibilidade de lucros, em um quadro de ameaças e oportunidades para a empresa.

Nesse contexto, o meio ambiente assume as características descritas por Buchholz (1992) como de uma questão estratégica para os negócios de uma empresa, a saber: a) coloca uma tendência ou oportunidade atual ou prospectiva; b) surge de alguma tendência ou desenvolvimento interno ou externo; c) pode ter um impacto potencial importante no crescimento, na rentabilidade ou na sobrevivência dos negócios; d) o curso ou impacto da questão podem, de alguma forma, ser influenciados pela ação da empresa.

Sob esse prisma, o meio ambiente gera uma nova perspectiva na agenda de negócios de empresas proativas, que pode ser estabelecida sob duas óticas distintas: o meio ambiente como base de negócios ou de desenvolvimento de idéias. Como base de negócios, o meio ambiente apresenta oportunidades e ameaças para os interesses dos negócios. A base de negócios pode 
identificar novas oportunidades para o desenvolvimento de processos, produtos e mercados, assim como para influenciar e alterar as exigências de consumo nos mercados já existentes, podendo, ainda, obrigar o fechamento de uma fábrica. Já como base de desenvolvimento de idéias, o meio ambiente contribui como parte de uma análise crítica da forma como a sociedade e os negócios operavam no passado, levantando questões acerca dos paradigmas existentes e a construção de novos paradigmas. A base de desenvolvimento de idéias coloca novas formas de pensamento e questões como o desenvolvimento sustentável e a responsabilidade ambiental (Roome, 1994).

Partindo dessas novas bases de negócios e de idéias, a empresa estabelece uma responsabilidade ambiental por processos e produtos que envolve um relacionamento diferente, compartilhado, com fornecedores e consumidores, no que se refere à prevenção da poluição, à minimização dos resíduos e à proteção dos recursos naturais. A essa responsabilidade, adicionamse outras, por questões ambientais mais difusas, como o bem-estar dos trabalhadores, da comunidade e até de gerações futuras. Isso obriga as empresas industriais a usarem horizontes de longo prazo e visões mais amplas de seus processos de desenvolvimento de produto e análise de desempenho. Com isso, requer-se um novo conjunto de valores, incluindo políticas e metas que incorporem a dimensão ambiental na organização.

Verifica-se, assim, que as empresas industriais que buscam uma postura proativa em relação às questões ambientais deparam-se com necessidades de mudanças que começam por seu próprio ambiente interno, mudanças essas que podem ser de diversos graus, conforme as especificidades da organização e as pressões existentes para que se adote uma postura diferenciada em relação ao meio ambiente. De uma maneira geral, as mudanças internas necessárias envolvem o reconhecimento da natureza interdisciplinar e interfuncional dos problemas ambientais, o que exige que as áreas funcionais da organização interajam e se integrem entre si, em termos de comunicação, de autoridade e de fluxo de trabalho. Também se requerem novas formas de relacionamento com os grupos de interesses da organização, como trabalhadores, consumidores, fornecedores, agências governamentais, comunidades, etc., para dar-lhes sinais de que esforços estão sendo concentrados para atender às suas exigências e para prever demandas futuras. Conseqüentemente, é buscada uma estrutura que suporte essa interação, integração e comunicação, interna e externa.

UMA EMPRESA QUE ADOTA
UMA POSTURA PROATIVA
DIANTE DOS IMPERATIVOS
AMBIENTAIS PRECISA INOVAR
NÃO SÓ SEUS PRODUTOS E
PROCESSOS MAS TAMBÉM
SUA ORGANIZAÇÃO.

Uma terceira necessidade de mudanças internas identificada é a busca de novas informações, seja sobre os impactos ambientais de processos e produtos, atuais e futuros; seja sobre conceitos, ferramentas, técnicas, tecnologias e sistemas para capturar esses impactos ambientais; seja sobre as exigências e tendências externas. Ao mesmo tempo, é preciso acolher formas de pensamento e análise que comportem as ambigüidades, complexidades e interdependências dessas informações. Requerem-se, assim, novos sistemas que comportem as novas tarefas, assim como talentos gerenciais para lidar com a dimensão ambiental.

Assim, uma empresa que adota uma postura proativa diante dos imperativos ambientais precisa inovar não só seus produtos e processos mas também, como coloca Roome (1994), sua organização. Ao realizar essas inovações - nos processos, nos produtos, nas estratégias e na organização -, as empresas industriais desenvolvem uma capacidade de se antecipar às exigências externas, dos governos, dos mercados ou da própria sociedade, mais do que esperar que essas exigências se desenvolvam e se tornem pressões para a adoção de práticas ambientais mais sustentáveis.

É interessante notar que a abordagem proativa não é restrita à gestão do meio ambiente, mas parte de uma tendência que está emergindo na admi- 
nistração em geral. Essa tendência é evidenciada nas obras e declarações de Peter Drucker (1992; Netz e Carvalho, 1995), Davidow e Malone (1993), Hamel e Prahalad (1994, 1995a, 1995b), entre outros autores, que incentivam as empresas a enxergarem mais longe e se anteciparem às mudanças, permitindo a obtenção de vantagens competitivas em seus mercados e também a criação de novos mercados. As prescrições sempre passam por reformas na organização que incluam a alteração das estruturas e sistemas, mudanças no pensamento ou nas filosofias e aprendizado de novos comportamentos e práticas da empresa industrial. Sendo assim, a gestão ambiental proativa também requer o tipo de reforma organizacional que é buscada para que os negócios sejam bem-sucedidos econômica e comercialmente.

\section{Tecnologias ambientais: emprego e gestão}

Um elemento fundamental para assegurar o desempenho econômico, produtivo e ambiental de uma empresa industrial é a utilização de tecnologias ambientais. O uso da tecnologia já vem se mostrando um fator importante nas últimas décadas para assegurar a rentabilidade e a competitividade da maioria das empresas industriais. No caso da proteção ambiental, as tecnologias ambientais envolvem:

a) tecnologias de controle de poluição (end-ofpipe), cujo principal objetivo é combater as saídas indesejáveis de resíduos do processo produtivo (poluição), sem realizar intervenções no próprio processo. Trata-se de equipamentos de controle de emissões e efluentes, tais como filtros purificadores, incineradores e redes de tratamento de água e esgoto, entre outros, que removem os resíduos poluentes ou reduzem sua toxicidade;

b) tecnologias de prevenção da poluição, centradas no processo produtivo para torná-lo mais eficiente, ou seja, ampliar a taxa de utilização dos insumos nos produtos fabricados. Essas tecnologias permitem não só reduzir os resíduos e poluentes na fonte mas também reutilizar ou reciclar os resíduos produzidos, preferencialmente ainda na planta industrial, voltando diretamente ao processo produtivo, e, em último caso, tratar os resíduos que não podem ser eliminados, reutilizados ou reciclados;

c) tecnologias de produtos e processos dentro do que foi conceituado pelo Programa das Nações Unidas para o Meio Ambiente (Pnuma) como a aplicação contínua de uma estratégia ambien- tal preventiva integrada aos processos e produtos para reduzir riscos aos seres humanos e ao meio ambiente (What..., 1994). Para os processos produtivos, a estratégia ambiental inclui a conservação de matérias-primas e energia, a eliminação de matérias-primas tóxicas e a redução da quantidade e toxicidade de todas as emissões e resíduos antes de deixarem o processo. Para os produtos, a estratégia concentra-se na redução de impactos por todo o ciclo de vida do produto, da extração das matérias-primas até a disposição final do produto.

$\mathrm{O}$ emprego de tecnologias de produtos e processos concorre para uma série de benefícios para uma empresa proativa ambientalmente, dentre os quais se podem destacar (Maimon, 1994; Donaire, 1994; Porter e Van der Linde, 1995a, 1995b; Roome, 1994; Shrivastava 1994/1995):

- melhorias na eficiência produtiva com menor utilização de energia e materiais por unidade de produto;

- minimização da quantidade de resíduos dispostos no meio ambiente;

- desenvolvimento de tecnologias mais limpas, que se transformam em vantagens competitivas e até mesmo em produto, com a possibilidade de auferir receitas com transferência de tecnologia, como, por exemplo, o licenciamento de patentes, a prestação de assistência técnica, etc.;

- desenvolvimento de novos produtos para novos mercados, seja mediante o reaproveitamento de resíduos e sua utilização como um novo produto, seja mediante o desenvolvimento de produtos com atributos ambientais;

- maior segurança pública e minimização dos impactos ambientais de produtos;

- melhoria da imagem pública e das relações com os órgãos governamentais, com a comunidade e grupos ambientalistas, permitindo até um maior escopo para auxiliar e influenciar os governos em novas regulamentações;

- melhoria nas condições de segurança e saúde dos trabalhadores e nas relações de trabalho;

- maior comprometimento de todo o staff da empresa. 
Entretanto, não é a mera posse da tecnologia que assegura o sucesso de sua implementação, mas sua apropriada gestão. Nesse sentido é que as empresas industriais que buscam a proteção ambiental vêm incorporando uma nova função administrativa em sua estrutura, com um corpo técnico específico e um sistema gerencial especializado. Essa nova função administrativa, um departamento ambiental na estrutura da organização, permite que a empresa industrial administre adequadamente suas relações com o meio ambiente, avaliando e corrigindo os problemas ambientais presentes, minimizando os impactos negativos futuros, integrando articuladamente todos os setores da empresa quanto aos imperativos ambientais e realizando um trabalho de comunicação ativo, interno e externo.

Em estudos realizados com empresas norte-americanas de diversos setores, Hunt e Auster (1995) verificaram que o departamento ambiental de empresas proativas é provido de pessoal com indivíduos determinados, motivados, de alto nível, que têm um conceito de gestão ambiental que vai muito além da idéia do policiamento e da prevenção da poluição. Esse departamento promove programas preventivos que se estendem por toda a organização, treina os empregados e promove a conscientização e responsabilidade ambiental em todos os níveis da organização, monitora as operações continuamente e trabalha rapidamente para corrigir problemas assim que ocorrem. Também há uma grande ligação entre a função ambiental e os níveis mais altos de administração, por meio de relações de informações diretas, encontros periódicos ou laços informais. Assim, as exigências e as metas quanto aos ditames ambientais são claras em todos os níveis da organização, e sistemas que facilitam o alcance dessas metas são constituídos em cada área da empresa. Adicionalmente, há uma forte atuação com os agentes reguladores, o próprio governo e também em comunidades locais.

Enfim, empresas industriais que adotam uma postura proativa em relação ao meio ambiente procuram continuamente se capacitar melhor para enfrentar os desafios ambientais e promover a proteção e a responsabilidade ambientais, tanto externamente quanto em suas estruturas organizacionais, buscando também garantir que os negócios sejam bemsucedidos econômica e comercialmente.

\section{É INTERESSANTE NOTAR QUE A ABORDAGEM PROATIVA NÃO É RESTRITA À GESTÃO DO MEIO AMBIENTE, MAS PARTE DE UMA TENDÊNCIA QUE ESTÁ EMERGINDO NA ADMINISTRAÇÃO EM GERAL.}

\section{Resistências à adoção de posturas proativas em relação ao meio ambiente}

Embora a direção da proteção e da responsabilidade ambientais pareça inevitável no contexto de mudanças das empresas industriais e favorável aos interesses dos negócios pelas melhorias na competitividade global da empresa, é ainda uma prática pouco difundida, como mostram pesquisas efetuadas com empresas da Comunidade Européia, que detectaram que a responsabilidade ambiental nem sempre faz parte da estratégia de uma empresa industrial, a não ser que esta receba sinais claros de exigências do mercado (Maimon, 1994). Por sua vez, uma pesquisa nos Estados Unidos, conduzida em 1992 pela Associação Nacional de Gerentes Ambientais, concluiu que a maioria das empresas que empregam gerentes ambientais o fazem por questões de conformidade às regulamentações, sendo que quase nenhuma delas pensa em termos de melhorias em projetos ou processos (Wheeler III, 1992). No Brasil, o quadro é mais dramático, uma vez que $75 \%$ das maiores empresas industriais do país nem possuem um sistema de gestão ambiental, segundo pesquisa realizada pela Price Waterhouse (Gomes, 1996). A maioria das empresas industriais, tanto no Brasil como nos países desenvolvidos, enfim, ainda não estão dando a devida importância à dimensão ambiental e a suas implicações para suas atividades de negócios, não desenvolvendo, assim, respostas adequadas.

A relutância em adotar uma postura proativa em relação aos imperativos ambientais fica expressa na profusão de reclamações quanto às políticas ambientais governamentais, quanto à sua rigidez, 
quanto à sua eficiência e especialmente quanto aos altos custos de conformidade, ${ }^{1}$ especialmente nos países desenvolvidos, nos quais os governos vêm intensificando sua ação nessa área. Alguma razão pode ser dada a essas críticas, se se considerar que os custos de conformidade às regulamentações ambientais podem ter um impacto adverso na lucratividade de setores ou empresas industriais que já têm menor competitividade no mercado. É o caso daqueles setores sujeitos a maiores custos de mão-de-obra, menor disponibilidade de capital ou atraso tecnológico, nos quais os custos ambientais representam uma compressão ainda maior das margens de lucro das empresas. Nesses casos, porém, os problemas não parecem se relacionar unicamente ao meio ambiente, e não seria só a política ambiental que afetaria o desempenho econômico-financeiro dos setores ou das empresas industriais em questão.

\section{O PAPEL DA ALTA}

ADMINISTRAÇÃO É

FUNDAMENTAL PARA QUE AS

INICIATIVAS E OS ESFORÇOS

DA ORGANIZAÇ̃̃O RUMO À PROTEÇÃO E ÀS RESPONSABILIDADES

\section{AMBIENTAIS TENHAM SUCESSO.}

Também não se pode negar que as regulamentações ambientais afetam a estrutura de custos das empresas industriais, mesmo das que não têm os problemas acima identificados. Dados da Organização para a Cooperação e Desenvolvimento Econômico (OCDE), porém, mostram que os custos de conformidade ambiental nos países membros que são os que em geral praticam as políticas ambientais mais restritivas - constituem em média menos de $3 \%$ dos custos totais ou de giro na maioria dos setores industriais (Stevens, 1993).

Uma série de iniciativas bem-sucedidas por parte de algumas empresas industriais pode, ainda, tornar alguns desses argumentos defensivos uma falácia. Sem discutir aqui a eficiência e efetividade das políticas ambientais dos governos em incentivar a busca de soluções alternativas, mais criati- vas, para os problemas ambientais, há efetivamente casos que não têm considerado a postura governamental como uma barreira, mas sim como uma base de lançamento de inovações, conseguindo benefícios internos e vantagens sobre muitos concorrentes que relutam ou retardam em segui-los. Alguns desses casos que se pode apontar são:

a) Forçada a obedecer a novas regulamentações norte-americanas para reduzir as emissões de solvente, a 3M, do setor químico, descobriu uma forma de evitar o uso dessa substância, substituindo-a por soluções aquosas. Tal mudança resultou não só numa melhoria de produtividade, por se tratar de substituição de um material por outro mais barato e mais seguro, mas também propiciou à empresa uma vantagem de liderança no desenvolvimento de produtos sobre os concorrentes, que a seguiram só mais tarde (Porter e Van der Linde, 1995a).

b) Atenta à gestão de resíduos, que está sob uma rigorosa legislação nos Estados Unidos, a Du Pont \& Co., empresa do setor químico, descobriu um novo produto químico, conhecido como HMI. A empresa verificou que o HMI, subproduto do processo produtivo do nylon, poderia ser usado nas indústrias farmacêutica e de tintas e, desde então, o HMI se tornou uma das principais fontes de lucro para a Du Pont (Wheeler III, 1992).

c) Empresas européias fabricantes de papel estão sujeitas a uma regulamentação de gestão de resíduos sólidos, que, em relação à regulamentação norte-americana, é mais rigorosa e está em vigor há muito mais tempo. No entanto, os fabricantes europeus conseguiram desenvolver uma infra-estrutura de gerenciamento de resíduos tão mais sofisticada que os norte-americanos que lhes está permitindo obter produtos de melhor qualidade, menos contaminados e conquistando fatias crescentes no mercado asiático, em detrimento dos fornecedores norte-americanos (Biddle, 1993).

d) Algumas pequenas destilarias indianas usavam tecnologias antigas e tradicionais para a produção de seus produtos, 
lançando um cheiro desagradável e substâncias tóxicas no meio ambiente. Verificando o enrijecimento das legislações ambientais em todo o mundo, essas destilarias buscaram uma organização internacional especializada que as ajudou a desenvolver e instalar um processo de tratamento que não só reduziu em $95 \%$ os resíduos tóxicos no meio ambiente mas também gerou um subproduto, o metano, que passou a ser utilizado como substituto energético, reduzindo também os custos de consumo de energia nas empresas (North, 1992).

Já outras empresas lidavam com problemáticas ambientais muito antes do advento recente da preocupação ambiental e das pressões regulamentares mais duras. Muitas questões de gestão ambiental eram abordadas, monitoradas e controladas por meio da produção diária, sem que fossem estabelecidos os conceitos e termos que utilizamos quanto aos problemas ambientais nem as pressões externas a que as empresas industriais estão sujeitas atualmente. Esse é o caso da Volkswagen, que reconheceu as considerações ambientais como um interesse operacional e estratégico somente no final da década de 80 . No entanto, desde a construção de sua primeira planta em Wolfsburg, na Alemanha, em 1938, a empresa vem considerando os aspectos ambientais, buscando a utilização de processos de produção baseados na minimização do uso de água e de sua reciclagem, devido à escassez de água na região próxima à fábrica (Welford, 1994).

Também os fabricantes do setor de papel inserem-se na mesma situação. Por exemplo, as norte-americanas Fort Howard Wisconsin Tissue Mills e Marcal já vêm usando a reciclagem de sobras de papel como fonte principal de seus processos de fabricação desde a década de 20. Fazendo isso, elas exploraram um recurso barato que lhes permitiu produzir produtos como lenços de papel em posições competitivas. Ao mesmo tempo, essas empresas não divulgavam publicitariamente que seus produtos continham fibra reciclada porque os consumidores no passado viam nisso uma indicação de baixa qualidade. Atualmente, ambas as empresas têm não só o apoio dos consumidores mas também o fornecimento crescente de sobras de papel pós-consumidas, especialmente por programas de reciclagem em escritórios. Como resultado, as duas empresas estão aumentando suas fatias de mercado por meio do próprio posicionamento como empresas que oferecem produtos ambientalmente responsáveis (Biddle, 1993).

EMBORA A DIREÇÃO DA

PROTEÇÃO E DA

RESPONSABILIDADE

AMBIENTAIS PAREÇA

INEVITÁVEL NO CONTEXTO DE

MUDANCAAS DAS EMPRESAS

INDUSTRIAIS E FAVORÁVEL AOS

INTERESSES DOS NEGÓCIOS

PELAS MELHORIAS NA

COMPETITIVIDADE GLOBAL DA

EMPRESA, É AINDA UMA

PRÁTICA POUCO DIFUNDIDA.

Tais exemplos podem representar uma possibilidade de mudança no comportamento e nos paradigmas da concorrência industrial e tratar a qualidade ambiental como uma fonte potencial de rentabilidade e vantagem competitiva. A indústria e as atividades industriais têm íntima relação com os problemas ambientais da sociedade moderna e também com as soluções para a reversão do processo. A indústria tem mostrado que, por meio da tecnologia e da racionalização, pode melhorar a eficiência em termos de uso dos recursos, substituir recursos escassos e reduzir o desperdício. Como exemplo, pode-se citar a Revolução da Qualidade, inicialmente implementada pelas indústrias japonesas e disseminada a partir da década de 70 por toda a indústria ocidental, que permitiu o surgimento de sistemas de produção enxutos (lean production), altamente produtivos. Também vale mencionar os "choques do petróleo" das décadas de 70 e 80, que elevaram os preços dos combustíveis fósseis e levaram à busca e utilização de energias alternativas, como o etanol produzido da canade-açúcar e utilizado por automóveis brasileiros. 
Trata-se de exemplos em que as indústrias foram desafiadas a encontrar novas formas de lidar com os problemas enfrentados. Atualmente, os desafios envolvem problemas globais, tanto o da crescente interdependência econômica mundial quanto o da crescente interdependência ambiental. A interdependência econômica é reconhecida no processo de globalização e pelas profundas mudanças nos mercados locais e internacionais que esse processo acarreta. Por outro lado, evidencia-se uma interdependência ambiental, embutida nesse processo de globalização econômica, adicionada a efeitos paralelos na forma de danos ambientais globais, diretos e indiretos, das atividades industriais, como o uso intensivo de recursos e o esgotamento de recursos naturais, a depreciação da camada de ozônio, a poluição, os acidentes industriais, entre outros.

\section{INDEPENDENTEMENTE}

DA FORMA QUE UMA

EMPRESA INDUSTRIAL

ESCOLHA REALIZAR SUAS

MUDANÇAS, AS QUESTÕES

AMBIENTAIS COLOCAM

PERMANENTEMENTE NOVOS

DESAFIOS À INDÚSTRIA.

Independentemente da forma que uma empresa industrial escolha realizar suas mudanças, engajando-se em iniciativas conjuntas de autoregulação ou agindo individualmente, as questões ambientais colocam permanentemente novos desafios à indústria que devem ser superados para garantir o sucesso e a própria continuidade dos negócios. Assim, faz-se necessária a gestão adequada dos problemas ambientais, integrando-a aos sistemas de gestão convencionais e permitindo que a organização avance para uma mais ampla aceitação dos conceitos e princípios ambientais, no desenvolvimento de técnicas e sistemas para capturar os impactos ambientais de produtos e processos e no reconhecimento da necessidade de uma reforma organizacional e gerencial para atingir melhores desempenhos ambientais.
O papel da alta administração é fundamental para que as iniciativas e os esforços da organização rumo à proteção e às responsabilidades ambientais tenham sucesso. Nesse sentido, novas abordagens têm surgido para que empresas industriais proativas e seus top-executivos reforcem um comprometimento da organização com a melhoria da qualidade do meio ambiente, como uma declaração de princípios ambientais e um plano estratégico ambiental, instrumentos gerenciais que serão vistos a seguir.

\section{INSTRUMENTOS GERENCIAIS DE PROMOÇÃO DA PROTEÇÃO E RESPONSABILIDADE AMBIENTAIS}

\section{Declaração de princípios ambientais}

Os estudos realizados por Hunt e Auster (1995), já citados, assim como os de North (1992) quanto à integração da dimensão ambiental na organização, constataram que, freqüentemente, é a média gerência que tem tomado as primeiras iniciativas quando a empresa se defronta com problemas ambientais, muitas vezes sem um apoio expresso por parte dos níveis mais altos até que uma certa maturidade no pensamento ambiental da empresa tenha sido atingida. No entanto, especialmente nos casos em que a alta administração assume efetivamente um comprometimento e apoio aos esforços de melhoria da qualidade ambiental dos processos e produtos da empresa é que tais esforços são bem-sucedidos. Dessa forma, o papel da alta administração é fundamental para perceber e modificar a sensibilização da organização quanto aos problemas ambientais, seja no ambiente externo da empresa, seja no interno.

O comprometimento da alta administração, na maioria dos casos, é formalizado mediante uma declaração de política corporativa, expressa em palavras, que integra as questões ambientais aos negócios da empresa. O propósito dessa formalização é não só divulgar o envolvimento na solução de problemas ambientais à própria organização mas também encorajar um compromisso de toda a empresa, além de tornar pública a decisão a outros grupos de interesses, como governos, consumidores, investidores e comunidades locais. 
Não há um modelo definitivo dessa declaração, mas algumas empresas adotam a Carta de Princípios para o Desenvolvimento Sustentável, da CIC, ou os Princípios Ceres, ou ainda os Princípios do Programa Atuação Responsável, especialmente se for do setor químico, ou se espelham neles.

O conteúdo de uma declaração de princípios ambientais não só menciona o comprometimento, mas também estabelece as metas básicas da empresa industrial em relação à causa ambiental. Nesse sentido, a maioria das declarações incluem a conformidade a todas as regras e regulamentações aplicáveis, assim como o comprometimento de cada empregado em verificar se essa conformidade é respeitada e assegurar que as operações e os produtos possam ser desenvolvidos de uma forma ambientalmente segura. Isso porque o gerenciamento da conformidade pode proteger uma empresa de ações mais drásticas decorrentes das regulamentações existentes.

Já uma abordagem mais proativa envolve também o gerenciamento do risco, a prevenção da poluição e a comunicação, o que ajuda a organização a administrar as políticas ambientais também para o futuro. Mediante o gerenciamento do risco, uma empresa industrial identifica danos potenciais e assegura que as prioridades estão sendo colocadas e os recursos, alocados de acordo com a prioridade de risco. Já a prevenção da poluição representa a minimização ou eliminação da poluição causada pela atividade industrial. A comunicação é um mecanismo que partilha a importância do sucesso ambiental da empresa com todos os empregados e os grupos de interesses.

Esses aspectos estão evidenciados na Política de Meio Ambiente da Rhodia S.A., que declara (Rhodia, 1992):

- "Minimizar a produção de efluentes e resíduos, por meio de tecnologias limpas e reciclagens: a redução de efluentes e resíduos, por meio de tecnologias limpas e processos de reciclagens, constitui o ponto fundamental de nossa política. A idéia básica: preferimos produzir menos efluentes e resíduos e obter melhores rendimentos, em vez de suportar os custos de tratamento.
- Dominar as poluições acidentais: como responsáveis, devemos desenvolver os instrumentos e as medidas necessários para impedir que possam ocorrer efeitos adversos ao meio ambiente devido ao mau funcionamento de nossas instalações. Isso é assegurado por meio de estudos de riscos, que envolvem equipes multidisciplinares de engenheiros. Tais estudos resultam em investimentos que garantem a diminuição dos riscos existentes. A prevenção de acidentes se faz por meio de estudos de riscos, que levam à melhoria dos processos de exploração, possibilitando a implementação de planos de emergência e a formação das pessoas envolvidas.

UMA ABORDAGEM MAIS
PROATIVA ENVOLVE TAMBÉM
O GERENCIAMENTO DO RISCO,
A PREVENÇÃO DA POLUIÇÃO E
A COMUNICAÇÃO, O QUE
AJUDA A ORGANIZAÇÃO A
ADMINISTRAR AS POLÍTICAS
AMBIENTAIS TAMBÉM
PARA O FUTURO.

- Gerenciar com rigor a eliminação de efluentes e resíduos: a gestão rigorosa da eliminação de resíduos e de efluentes líquidos e gasosos deve ser feita não somente em respeito à legislação, mas utilizando a melhor tecnologia disponível e economicamente compatível.

- Desenvolver e comercializar produtos com um estrito respeito à saúde humana e ao meio ambiente: o respeito à saúde humana e ao ecossistema não é uma preocupação recente da Rhodia. (...) Cada etapa de vida de um produto - da concepção à destruição - deve considerar a proteção ao meio ambiente.

- Desenvolver a comunicação interna e externa: (...) Em relação ao público externo, e conforme o conceito de 'portas abertas', enfatizamse a maior integração das fábricas com as comunidades vizinhas às suas instalações e a valorização do diálogo com as autoridades, os órgãos de controle ambiental e a imprensa. A Rhodia dispõe de ferramentas de gestão - os 
Índices de Meio Ambiente - que permitem uma melhoria na comunicação interna de seus objetivos e na comunicação com o público externo."

No entanto, uma declaração por si mesma não é o suficiente. A fim de que a declaração não fique só na formalidade, ela é traduzida para as políticas e práticas da empresa, o que normalmente é feito mediante a elaboração de um plano estratégico ambiental.

\section{Plano estratégico ambiental}

Os planos ambientais estabelecem a política estratégica da empresa diante dos imperativos ambientais, determinando as metas a serem atingidas, assim como as medidas a serem utilizadas para implementar a estratégia, avaliar seu resultado e estabelecer novos planos.

O conteúdo dos planos ambientais varia de empresa para empresa, mas as que se voltam para os princípios da sustentabilidade e responsabilidade ambientais geralmente utilizam requisitos internos ou metas até mais restritivos que os legalmente impostos, adotando uma abordagem integrada das questões ambientais em sua estratégia de negócios. Alguns aspectos que normalmente são observados nessa abordagem integrada são os seguintes:

- prioridade à saúde e segurança dos empregados, dos consumidores e da comunidade;

- promoção de políticas que evitem os recursos escassos, espécies em extinção e apoio a regimes opressivos;

- influência direta da política ambiental nos processos de fabricação, práticas de manutenção e emissões;

- influência da política ambiental no projeto de produtos e processos de formas diretas e explícitas;

- redução, reuso e reciclagem de materiais;

- monitoração e mensuração das emissões;

- redução do uso e de emissão de substâncias tóxicas;

- recuperação de produtos e embalagens após o uso, para reuso e reciclagem;

- treinamento ambiental aos empregados;

- melhoria ambiental contínua;

- contabilidade de custos ambientais.

Ao elaborar seu plano ambiental, muitas empresas sentem necessidade de quantificar seus objetivos e medir seu desempenho ambiental. É o caso da fábrica da Du Pont em Paulínia, SP, que se comprometeu em reduzir em $30 \%$ o consumo de água, mesmo não tendo custos com a água que consome, a qual é retirada de um poço artesiano instalado em sua própria planta (Gomes, 1996). As metas quantitativas servem como incentivo para o esforço geral da organização e são normalmente determinadas dentro de parâmetros possíveis de serem alcançados.

Para se implantar metas ambientais como essa, as empresas precisam primeiramente conhecer seu estado-atual-da-arte no campo ambiental, seja quanto às exigências dos grupos de interesses, seja quanto aos seus impactos no meio ambiente. Em seguida, necessitam planejar suas ações e estabelecer um conjunto de práticas e procedimentos que permita administrar as relações empresa-meio ambiente, monitorando suas atividades, corrigindo problemas, implementando novas soluções, avaliando riscos e adotando medidas preventivas dentro da política e dos objetivos determinados pelo plano estratégico ambiental.

\section{CONCLUSÃO}

O setor industrial passa por um importante período de transição e ajustes diante dos imperativos ambientais, que inclui, de um lado, o tratamento do meio ambiente como uma questão estratégica e fonte potencial de rentabilidade e vantagem competitiva e, de outro, a busca de soluções para os problemas ambientais, atuais e futuros. As empresas industriais estão sendo desafiadas a encontrar novas formas de organização e administração da produção que atendam às exigências ambientais e que representem uma participação ativa do empresariado no processo de mudanças de comportamento necessário para que as expectativas da sociedade relativas à melhoria da qualidade de vida sejam atingidas.

Há uma área específica de problemática referente à tecnologia como solução para os ditames ambientais, mas verifica-se ainda a necessidade de uma gestão adequada de outras questões relacionadas ao meio ambiente que permitam que uma organização industrial e a própria sociedade avancem rumo a uma mais ampla aceitação dos conceitos e princípios ambientais. Essas outras questões relacionam-se à possibilidade de se conciliar a expansão econômica 
e o avanço industrial e tecnológico com a preservação ambiental, que evidenciam o próprio conflito da sociedade atual, que é o de aliar o crescimento à qualidade de vida, de crescer sem destruir, de garantir a sua futuridade.

De fato, no que se refere ao meio ambiente, é exatamente o problema com o qual a sociedade moderna se depara. Depois de períodos de crescimento contínuo e explosivo, de adoção de modelos de desenvolvimento que viabilizassem o crescimento a qualquer preço, especialmente nos países em desenvolvimento, a sociedade hoje questiona o preço pago por todo esse esforço. O meio ambiente se tornou um elemento-chave para se repensar os valores e as ideologias vigentes e se estabelecer novas formas de pensamento e ação em todas as práticas produtivas. $\mathrm{O}$ meio ambiente tem-se tornado um elemento vital para se estabelecer os novos paradigmas da concorrência industrial e, por isso, aflora como importante questão para se estabelecerem os rumos futuros dos mercados e da sociedade, locais ou globais. Mesmo que soe "piegas" falar sobre meio ambiente e proteção ambiental.
REFERÊNCIAS BIBLIOGRÁFICAS

BIDDLE, David. Recycling for profit: the new green business frontier. Harvard Business Review, v. 71, n. 6, p. 145-56, Nov./Dec. 1993.

BUCHHOLZ, Rogene A. Business environment and public policy: implications for management and strategy. 4. ed. Englewood Cliffs, N.J. Prentice-Hall, 1992. p. 466-7. (1. ed.: 1982).

CORDTZ, Dan. Green hell. Financial World, v. 163 , n. 2, p. 38-42, Jan. 18, 1994

DAVIDOW, William H., MALONE, Michael S. $A$ corporação virtual: estruturação e revitalização da corporação para o século 21. São Paulo: Pioneira, 1993

DONAIRE, Denis. Considerações sobre a influência da variável ambiental na empresa Revista de Administração de Empresas, v. 34 n. 2, p. 68-77, mar./abr. 1994

DONAIRE, Denis. Gestão ambiental na empresa São Paulo: Atlas, 1995. p. 36-7.

DRUCKER, Peter F. Administrando para o futuro: os anos 90 e a virada do século. São Paulo: Pioneira (Biblioteca Pioneira de Administração Negócios), 1992.

GOMES, Maria T. 0 verde que vem antes do jardim. Exame, ed. 608, ano 29, n. 9, p. 66-7, 24 abr. 1996.

HAMEL, Gary, PRAHALAD, C. K. Competing for the future. Harvard Business Review, v. 72, n. 4 p. 122-28, July/Aug. 1994
HAMEL, Gary, PRAHALAD, C. K. Competindo pelo futuro. Rio de Janeiro: Campus, 1995a.

HAMEL, Gary, PRAHALAD, C. K. Como se armar para competir pelo futuro. Exame, ed. 579, ano 27 , n. 6 , p. $79-82,15$ mar. 1995 b.

HUNT, Christopher B., AUSTER, Ellen R. Proactive environmental management: avoiding the toxic trap. Sloan Management Review, v. 31 n. 2, p. 7-18, Spring 1995.

MAIMON, Dália. Eco-estratégia nas empresa brasileiras: realidade ou discurso? RAE - Revista de Administração de Empresas, v. 34, n. 4, p. 119-30, jul./ago. 1994

NETZ, Clayton, CARVALHO, Sandra. Entrevista com Peter Drucker. Exame Entrevista, p. 32-5 dez. 1995. (Edição especial).

NORTH, Klaus. Environmental business management: an introduction. Geneva: International Labour Office, 1992. p. 35. (Management Development Series, n. 30).

PORTER, Michael E., VAN DER LINDE, Claas. Green and competitive: ending the stalemate. Harvard Business Review, v. 73, n. 5, p. 120 34, Sep./Oct. 1995a.

PORTER, Michael E., VAN DER LINDE, Claas. Se verde também é ser competitivo. Exame, ed. 597 ano 28 , n. 24 , p. $72-8,22$ nov. 1995 b.

POTIER, Michel. Agreement on the environment. The OECD Observer, n. 189, p. 8-11, Aug./Sep. 1994.

RHODIA. Relatório de meio ambiente. Rhodia S.A., 1992.
R00ME, Nigel. Business strategy, R\&D management and environmental imperatives. R\&D Management, v. 24, n. 1, p. 65-82, 1994.

SHRIVASTAVA, Paul. Environmental technologies and competitive advantage. Strategic Management Journal, v. 16, p. 183-200, Summer 1994/1995. (Special issue).

STEVENS, Candice. Do environmental policies affect competitiveness? The OECD Observer, $\mathrm{n}$. 183, p. 22-5, Aug./Sep. 1993

WALLEY, Noah, WHITEHEAD, Bradley. It's not easy being green. Harvard Business Review, v. 72, n. 3, p. 46-52, May/June 1994a.

WALLEY, Noah, WHITEHEAD, Bradley. Noah Walley and Bradley Whitehead respond: The challenge is to figure out how fast and how far to go. Harvard Business Review, v. 72, n. 4 p. 48-9, Jul./Aug. 1994 b.

WALLEY, Noah, WHITEHEAD, Bradley. Plantar árvores não é brincadeira. É um negócio sério. Exame, ed. 570, ano 26, n. 23, p. 59-62, 9 nov. $1994 c$.

WELFORD, Richard. Cases in environmental management and business strategy. London: Pitman Publishing, 1994. p. 80-1.

WHAT is cleaner production and the cleane production programme? UNEP Industry and Environment, v. 17, n. 4, p. 4, Oct./Dec. 1994.

WHEELER III, William A. The revival in reverse manufacturing. Journal of Business Strategy, v. 13, n. 4, p. 8-13, July/Aug. 1992
NOTAS

Este artigo foi produzido a partir da Dissertação de Mestrado $A$ evolução da prática ambiental em empresas industriais: algumas considerações sobre 0 estado-atual-da-arte e o caso brasileiro, apresentada à EAESP-FGV, sob a orientação do Prof. Dr. José Carlos Barbieri e com apoio financeiro da Capes (Fundação Coordenação de Aperfeiçoamento de Pessoal de Níve Superior).

1. Essa postura é evidenciada em Cordtz (1994). 0 autor apresenta firmas, trabalhadores e cidadãos comuns norteamericanos atacando as regras ambientais alegando questões de custos e de direitos. Também os artigos de Walley e Whitehead $(1994 a, 1994 b, 1994 c)$ defendem esse posicionamento, acrescentando os efeitos na competitividade industrial do país. 